\title{
Syntactic structure analysis in uveal melanomas
}

\author{
Kate Coleman, Paul J van Diest, Jan P A Baak, Joan Mullaney
}

\begin{abstract}
Syntactic structure analysis was carried out successfully on 92 paraffin embedded uveal melanomas, taken from patients with a minimum follow up of 5 years. This simple, fast, and reproducible method of describing the tumour architecture has been significantly correlated with malignancy in tumours from several sites. Paraffin sections $5 \mu \mathrm{m}$ thick, were cut and stained with haematoxylin and eosin. Tumours were classified according to a modification of the Callender classification. A minimum spanning tree (MST), using the centre points of tumour nuclei, was constructed in five randomly chosen fields with an interactive digitising video overlay system. Ten syntactic structure features were derived from each MST; subsequently, the mean and standard deviation of the five fields analysed were calculated for further statistical analysis. Reproducibility was acceptable with a mean correlation coefficient of $\mathbf{0 \cdot 7 0}$. In univariate survival analysis, the percentage of points with three neighbours yielded prognostic significance $(\mathbf{p}<0.05)$. Minimum spanning tree variables were compared ( $\chi^{2}$ test) with classic tumour prognosticators and there was a significant correlation between Callender cell type and the following MST parameters: mean number of points $(p<0.003)$; MST length $(p<0.003)$; mean line length $(p<0.01)$; number of nuclei with one neighbour $(p<0.004)$; number of nuclei with two neighbours $(p<0.02)$, and number of nuclei with three neighbours $(p<0.005)$. Syntactic structure analysis is an evolving technique, but may be able to mathematically (and reproducibly) describe melanoma architecture across the spectrum of the Callender classes. This would also allow architectural grading of tumours within the specific Callender groups, providing more precise prognostic information. Further modifications of this technique are necessary to optimise prognostic potential when applied to uveal melanomas.
\end{abstract}

Departments of Research and Pathology, The Royal Victoria Eye and Ear Hospital, Dublin, Ireland

K Coleman

J Mullaney

Department of

Pathology, The Free

University Hospital,

Amsterdam, the

Netherlands

$P$ J van Diest

J P A Baak

Correspondence to: Dr Kate Coleman, The Research Foundation, The Royal Victoria Eye and Ea Hospital, Adelaide Road, Dublin 2, Ireland.

Accepted for publication 7 July 1994

behaviour, ${ }^{3}$ as shown by a modification of the Callender system in $1983 .{ }^{4}$ In a large series of 740 melanomas from the Armed Forces Institute of Pathology, Washington, DC, Gamel et al have demonstrated that the largest tumour dimension (LTD) and nucleolar characteristics, both the standard deviation of nucleolar area (SDNA) and the mean of the 10 largest nucleoli (MTLN), contribute equally with cell type to tumour prognosis. Furthermore, they demonstrated a poor correlation between LTD and cell type and between nucleolar variables and cell type, suggesting that cell type relies largely on cytological features other than nucleolar size for its prognostic value, and that tumour size is not related closely to current measurements of cytological features. ${ }^{5}$ DNA quantitation has also been correlated with cell type ${ }^{6}$ and in one study was a superior prognosticator to the inverse SDNA. Recently, nucleolar organiser regions (AgNORs) have been correlated with the inverse SDNA $(p<0.0001)$ and LTD $(p<0.0003)$ as part of the Collaborative Ocular Melanoma Study (COMS), although they do not differentiate between the epithelioid and the mixed/spindle cell tumours. ${ }^{8}$

The key connection between macroscopic LTD, microscopic histopathological variables, nucleolar features, and patient survival may lie in the tumour architecture. Since 1981, several investigators have been applying simple variations of the graph theory to analyse tumours from different sites at a relatively low magnification. ${ }^{-11}$ In the graph theory, any structure in which certain elements can be distinguished can be described by reducing the elements to points, interconnecting the points with lines, and using a function (the incidence function) to describe the way in which the points are connected by the lines. Syntactic structure analysis, derived from the graph theory, is a simple, fast, mathematical method of describing the basic structural units such as cells, glands, and vessels as a network. Different approaches of the basic graph have been applied, depending on the tissue under examination. One popular approach has been the construction of the minimum spanning tree $(M S T)^{12}$ where a set of points is joined in such a way that the sum of the lengths of the connecting lines is minimal. The principles of the MST are outlined in Figure 1. A major advantage of the MST approach is that it is independent of anisotropic tumour characteristics (for example, angle of tumour section, direction of fascicles). Syntactic structure analysis has been significantly correlated with tumour behaviour in tumours of the lung, ${ }^{13}$ prostate,${ }^{14}$ pleura, ${ }^{15}$ colon, ${ }^{16}$ endometrium,${ }^{17}$ and breast. ${ }^{18}$ We carried out a pilot study to examine the role of syntactic structure analysis, using MST features, as a predictor of prognosis in uveal melanomas.

\section{Materials and methods}

Uveal melanomas from 92 patients who were referred to the Eye and Ear Hospital, Dublin between 1964 and 1987, were selected from a total group of 113 patients, depending on 


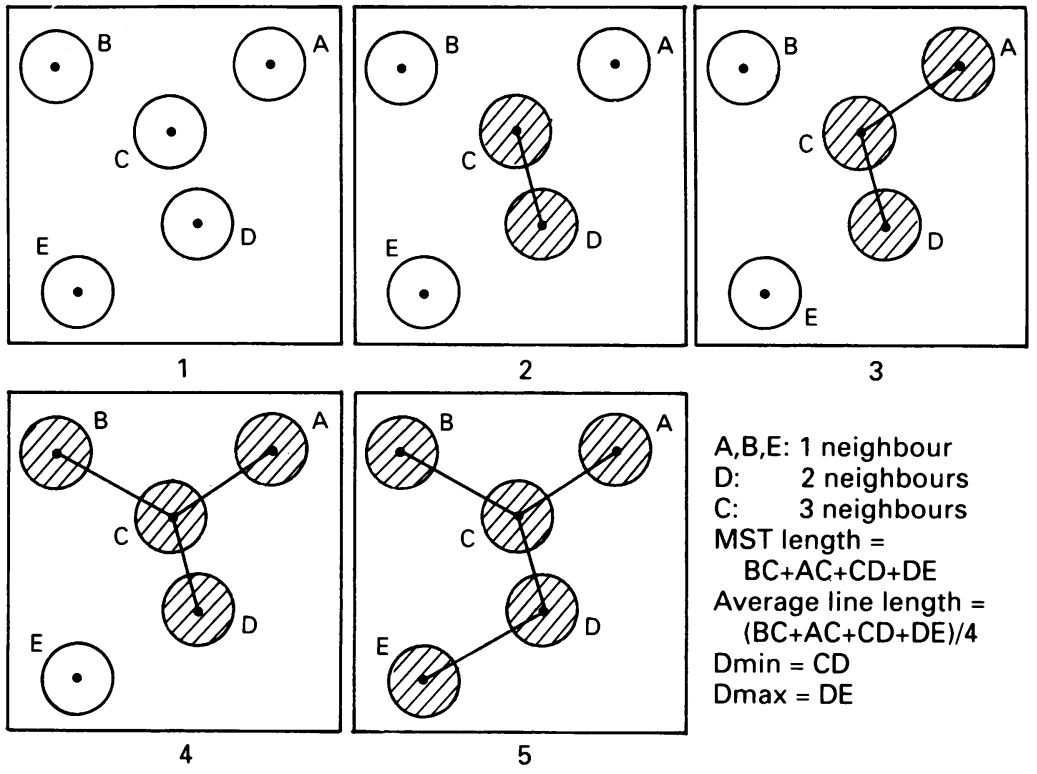

Figure 1 Schematic explanation of the algorithm for building the minimum spanning tree and calculation of the related minimum spanning tree features. Block 1: field containing five nuclei with their centroids marked. Block 2: after calculating the distances between all the centroids, the distance between $C$ and $D$ has been found to be the shortest, so $C$ and $D$ are connected by $a$ line. Block 3: of the remaining free centroids, $A$ is closest to one of the centroids already connected to the tree, namely $C$, so $A$ and $C$ are connected. Block 4: of the remaining free centroids, $B$ is closest to one of the centroids already connected to the tree, namely $C$, so $B$ and $C$ are connected. Field 5: the last remaining free centroid, $E$, is closest to $D$, so $E$ is taken into the tree by connecting $E$ with $D$. The minimum spanning tree is now completed for this field, and the features calculated from it are shown at the bottom right. the suitability of the histological material for MST analysis. Each patient had undergone enucleation shortly after the diagnosis of their melanoma, and no other form of treatment was used before surgery. Twenty eight patients died with metastases. The maximum follow up time was 24 years, the median 11 years, and the minimum, 5 years. The Callender classification was modified for the purpose of this study, in an attempt to identify mixed tumours with predominantly spindle cells, as opposed to mixed tumours with predominantly epithelioid cells. Tumours were classified as follows: two spindle A; 28 spindle $\mathrm{B} ; 11$ spindle $\mathrm{A} / \mathrm{B}$ mixed; 32 predominantly spindle plus a few epithelioid; and 19 predominantly epithelioid plus a few spindle. Two of the 92 melanomas originated in the iris, were spindle B tumours, and were not associated with metastasis. No direct statistical comparison with choroidal melanoma was possible because of the small number involved. Tumour specimens were fixed in $2 \%$ buffered glutaraldehyde and $4 \%$ buffered formalin, and embedded in paraffin according to standard procedures. Sections were cut $5 \mu \mathrm{m}$ thick and stained with haematoxylin and eosin.

\section{SYNTACTIC STRUCTURE ANALYSIS}

Syntactic structure analysis was done with the PRODIT digitising interactive video overlay system (BMA, De Meern, the Netherlands), which is composed of a video camera mounted on a microscope and linked to a video overlay board in a microcomputer.

The tumour was demarcated and five fields were chosen randomly with an automatic scanning stage. For these five fields, syntactic structure analysis was carried out by constructing an MST. This is summarised as follows. The centres of gravity of all nuclei per field of vision were interactively marked on a video screen by setting a point with the cursor. Using this set of points, the computer composed the MST. Figure 1 shows schematically how an MST is built and explains the meaning of the different spanning tree features.
The optimal and most practical magnification for choroidal melanomas was chosen by first measuring four tumours using both $\times 63$ and $\times 40$ objectives. Using a $286 / 287$ processor based system, it took an average of 5 minutes to produce an MST with a mean of 78 points per field with the $\times 63$ objective, as opposed to 20 minutes with a mean of 257 points using the $\times 40$ objective. The $\times 63$ objective (final magnification $\times 1900$ ) was thus selected as the most efficient for the purpose of this study.

The following syntactic structure features were derived from the MST composed in each field: number of points, length of the MST, average line length, and number and percentages of points with one neighbour, two neighbours, three neighbours, four neighbours, and five neighbours. For each of these features, the mean, SD, minimum, and maximum values of the five fields analysed were calculated. Five neighbours (the maximum for the algorithm used) appeared to be rare and the statistics of this feature were not analysed further.

The intraobserver reproducibility of the method was tested by analysing five patients twice.

\section{STATISTICS}

Linear regression analysis was performed to assess the reproducibility of the duplicate measurements. Only variables showing reasonable reproducibility (correlation coefficient $>0.50$ ) were considered for further survival analysis. Correlations between the MST variables and classic variables (that is, LTD, cell type, glaucoma, and retinal detachment) were evaluated using the $\chi^{2}$ test.

For survival analysis, patients dying without clinically evident metastases were censored at that date and corrected (tumour related) survival time was used as the follow up parameter. For univariate survival analysis, grouping was performed according to the different subgroups for each non-continuous variable. For LTD, cut off points were chosen at $10 \mathrm{~mm}$ and $15 \mathrm{~mm}$ according to the literature. For the remaining continuous variables, cut off points were chosen in such a way that approximately equal subgroups resulted. Kaplan-Meier curves were plotted, and the differences between the curves analysed with the Mantel-Cox test. Multivariate survival analysis (Cox proportional hazards model) was performed to evaluate additional prognostic value of the varilables studied, using enter and remove limits of $0 \cdot 10$. All statistical tests were carried out with the BMDP statistical package, regarding probability values below 0.05 as significant.

\section{Results}

Table 1 displays the $p$ values and Mantel-Cox values for the MST parameters that were further tested. All variables listed in Table 1 showed correlation coefficients for intraobserver reproducibility ranging from $0 \cdot 50-0 \cdot 86$, with a mean of $0 \cdot 70$.

The percentage of points with three neighbours provided significant prognostic value 
Table 1 Univariate survival analysis of minimum spanning tree (MST) variables in 92 uveal melanomas

\begin{tabular}{|c|c|c|c|c|c|c|}
\hline $\begin{array}{l}\text { Variable } \\
\text { (mean value) }\end{array}$ & $\begin{array}{l}\text { Cut off } \\
\text { points }\end{array}$ & $n$ & $\begin{array}{l}\text { Metastases } \\
(n)\end{array}$ & $\begin{array}{l}\text { Alive } \\
(\%)\end{array}$ & p Value & $\begin{array}{l}\text { Mantel- } \\
\text { Cox }\end{array}$ \\
\hline Points (n) & $\begin{array}{l}\leqslant 73 \cdot 7 \\
>73-7\end{array}$ & $\begin{array}{l}46 \\
46\end{array}$ & $\begin{array}{l}15 \\
13\end{array}$ & $\begin{array}{l}67 \\
72\end{array}$ & 0.89 & 0.02 \\
\hline MST length & $\begin{array}{l}\leqslant 638 \\
>638\end{array}$ & $\begin{array}{l}46 \\
46 \\
\end{array}$ & $\begin{array}{l}15 \\
13\end{array}$ & $\begin{array}{l}67 \\
72\end{array}$ & $0 \cdot 86$ & 0.03 \\
\hline Mean line length & $\begin{array}{l}\leqslant 8.67 \\
>8.67\end{array}$ & $\begin{array}{l}45 \\
47\end{array}$ & $\begin{array}{l}11 \\
17\end{array}$ & $\begin{array}{l}76 \\
64\end{array}$ & 0.38 & 0.76 \\
\hline Line length (min) & $\begin{array}{l}\leqslant 3.84 \\
>3.84\end{array}$ & $\begin{array}{l}46 \\
46\end{array}$ & $\begin{array}{l}15 \\
13\end{array}$ & $\begin{array}{l}67 \\
72\end{array}$ & 0.97 & 0.002 \\
\hline Line length ( $\max )$ & $\begin{array}{l}\leqslant 15.4 \\
>15.4\end{array}$ & $\begin{array}{l}46 \\
46\end{array}$ & $\begin{array}{l}12 \\
16\end{array}$ & $\begin{array}{l}74 \\
65\end{array}$ & 0.38 & $0 \cdot 78$ \\
\hline Line length (SD) & $\begin{array}{l}\leqslant 2 \cdot 31 \\
>2 \cdot 31\end{array}$ & $\begin{array}{l}45 \\
47\end{array}$ & $\begin{array}{l}14 \\
14\end{array}$ & $\begin{array}{l}69 \\
70\end{array}$ & $0 \cdot 80$ & 0.06 \\
\hline 1 Neighbour (n) & $\begin{array}{l}\leqslant 19.5 \\
>19.5\end{array}$ & $\begin{array}{l}46 \\
46\end{array}$ & $\begin{array}{l}16 \\
12\end{array}$ & $\begin{array}{l}65 \\
74\end{array}$ & 0.49 & 0.48 \\
\hline 1 Neighbour (\%) & $\begin{array}{l}\leqslant 26 \cdot 1 \\
>26 \cdot 1\end{array}$ & $\begin{array}{l}45 \\
47\end{array}$ & $\begin{array}{l}11 \\
17\end{array}$ & $\begin{array}{l}76 \\
64\end{array}$ & 0.68 & $0 \cdot 17$ \\
\hline 2 Neighbours (n) & $\begin{array}{l}\leqslant 38 \cdot 5 \\
>38 \cdot 5\end{array}$ & $\begin{array}{l}47 \\
45\end{array}$ & 17 & $\begin{array}{l}64 \\
76\end{array}$ & $0 \cdot 25$ & $1 \cdot 3$ \\
\hline 2 Neighbours (\%) & $\begin{array}{l}\leqslant 51 \cdot 8 \\
>51.8\end{array}$ & $\begin{array}{l}46 \\
46\end{array}$ & $\begin{array}{l}17 \\
11\end{array}$ & $\begin{array}{l}63 \\
76\end{array}$ & 0.43 & 0.63 \\
\hline 3 Neighbours (n) & $\begin{array}{l}\leqslant 15 \cdot 5 \\
>15 \cdot 5\end{array}$ & $\begin{array}{l}44 \\
48\end{array}$ & $\begin{array}{l}14 \\
14\end{array}$ & $\begin{array}{l}68 \\
71\end{array}$ & 0.53 & 0.39 \\
\hline 3 Neighbours (\%) & $\begin{array}{l}\leqslant 21.05 \\
>21.05\end{array}$ & $\begin{array}{l}45 \\
47\end{array}$ & $\begin{array}{r}9 \\
19\end{array}$ & $\begin{array}{l}80 \\
60\end{array}$ & 0.05 & $3 \cdot 6$ \\
\hline 4 Neighbours (n) & $\begin{array}{l}\leqslant 0.9 \\
>0.9\end{array}$ & $\begin{array}{l}43 \\
49\end{array}$ & $\begin{array}{l}16 \\
12\end{array}$ & $\begin{array}{l}63 \\
76\end{array}$ & $0 \cdot 24$ & $1 \cdot 4$ \\
\hline 4 Neighbours (\%) & $\begin{array}{l}\leqslant 1 \cdot 27 \\
>1 \cdot 27\end{array}$ & $\begin{array}{l}46 \\
46\end{array}$ & $\begin{array}{l}15 \\
13\end{array}$ & $\begin{array}{l}67 \\
72\end{array}$ & 0.97 & 0.001 \\
\hline
\end{tabular}

Figure 2 Survival curve of 92 patients with uveal of points with three neighbours. melanoma for the percentage

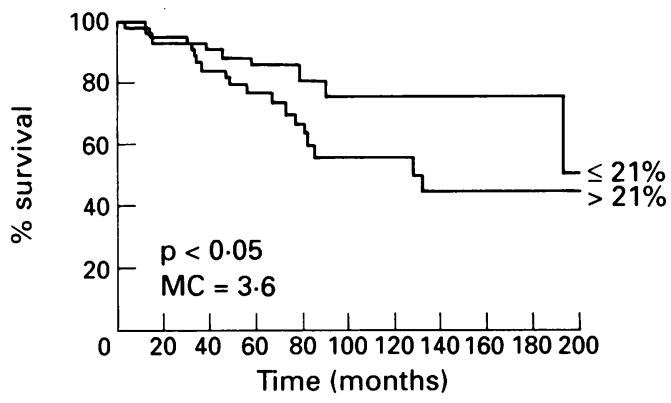

$\begin{array}{lllllll}\text { At risk } & 45 & 39 & 18 & 10 & 6 & 1 \leq 21 \% \\ 47 & 37 & 19 & 10 & 1 & 1>21 \%\end{array}$

( $p<0 \cdot 05$, Mantel-Cox value 3.6). The survival curve is shown in Figure 2. In multivariate analysis, none of the MST variables showed additional prognostic value to significant variables, as established in a previous report of analysis of this group of melanomas ${ }^{19}$ (such as LTD, cell type, glaucoma, or retinal detachment).

There was a significant correlation between cell type and the following MST parameters (see Table 2): mean number of points $(p<0.003)$; MST length $(p<0.003)$; mean line length $(\mathrm{p}<0.01)$; number of points with one neighbour $(\mathrm{p}<0.004)$; number of points with two neighbours $(p<0.02)$; and number of points with three neighbours $(\mathrm{p}<0.005)$.

Table 2 Correlation of minimum spanning tree parameters (MST) with classic uveal melanoma prognosticator

\begin{tabular}{llllll}
\hline Parameter(mean value) & Metastases & Cell type & $R D$ & Glaucoma & LTD \\
\hline Points (n) & NS & $\mathrm{p}<0.003$ & NS & NS & NS \\
MST length & NS & p $<0.003$ & NS & NS & NS \\
Mean line length & NS & p $<0.01$ & NS & NS & NS \\
Line length (SD) & NS & NS & NS & NS & NS \\
1 Neighbour (n) & NS & p $<0.004$ & NS & NS & NS \\
1 Neighbour $(\%)$ & NS & NS & NS & NS & NS \\
2 Neighbours (n) & NS & p $<0.02$ & p $<0.05$ & NS & NS \\
2 Neighbours (\%) & NS & NS & NS & NS & NS \\
3 Neighbours (n) & NS & p $<0.005$ & NS & NS & NS \\
3 Neighbours (\%) & p $<0.008$ & NS & NS & NS & NS \\
\hline
\end{tabular}

$\mathrm{RD}=$ retinal detachment $\mathrm{LTD}=$ largest tumour dimension; $N S=$ not significant.

\section{Discussion}

In this preliminary study, syntactic structure analysis of 92 uveal melanomas by construction of the MST showed the percentage of nuclei with three neighbours to be prognostically significant $(\mathrm{p}<0.05)$. In multivariate analysis, MST variables did not provide any additional prognostic information to LTD, cell type, or glaucoma but there was a strong correlation between MST variables and cell type.

The relevance of number of neighbours per tumour cell depends on the tissue under observation. A tubular adenomatous structure would be characterised by the presence of a maximum of two neighbours per cell, whereas the presence of an average of three to five normally distributed neighbours is more typical of solid tissue such as liver, brain, or muscle. ${ }^{20} \mathrm{~A}$ cycling tumour cell will produce first generation stem cells that would be expected to be more closely related to it geometrically than second generation cells. In a study of lung carcinomas, Kayser et al demonstrated that tumour cell nuclei of epidermoid cell lesions, with two to three neighbours, showed a higher DNA content than the isolated tumour cell nuclei. Exactly the opposite was demonstrated for large cell anaplastic carcinoma. ${ }^{13}$ Van Diest $e t$ al strongly correlated mean and standard deviation values of nuclear area, volume percentage epithelium, and mitotic activity index with MST analysis of invasive breast carcinoma. ${ }^{20} \mathrm{It}$ is possible that the significant correlation of the percentage of nuclei with three neighbours in uveal melanoma cells with metastatic death may also reflect increased nucleolar activity and cell proliferation.

We were particularly interested in the relation between syntactic structure analysis and the Callender classification. Spindle cells and epithelioid cells, while obeying the basic Callender criteria for classification, vary considerably in size and arrangements from tumour to tumour, hence the difficulties encountered with reproducibility of this classification. ${ }^{21}$ The fascicular arrangement of the spindle cell categories, in contrast with the more haphazard (and more malignant) mixed and epithelioid cell categories, suggested a possible architectural association with poor prognosis. The strong correlation between Callender cell type and MST analysis may indeed provide a numerical parameter reflecting these differences. Comparing MSTs from epithelioid and spindle cell tumours, it could be seen that the cohesive fascicular arrangement of the spindle cells was associated with shorter distances between nuclei and an increase in points per field. The epithelioid cells reflect the pleomorphism, obvious nucleoli, and loss of cohesiveness typical of cells with more aggressive behaviour.

A major advantage of construction of an MST over conventional morphometric measurements is that it is unaffected by anisotropic properties of the tumour cells. ${ }^{13} \mathrm{~A}$ tree drawn of a cross section of spindle cells provides the same results as one constructed of cells aligned in the same plane. However, one of the dilemmas posed by the current use of the Callender classification is the separation of mixed cell tumours into prognostically significant categories. An MST drawn 
in a spindle area of such a tumour would have very different features to that drawn in an epithelioid cell region. The average MST over five fields would not necessarily reflect this variation. This raises the question of the method of syntactic structure analysis best suited to uveal melanomas.

To date, four methods of application have been used, and the condition for the most appropriate algorithm depends on the organ studied. Voronoi's neighbourhood condition was first described in 1902 and uses each point in the field (for example, the nucleus) as the centre of a circle. Connections between circles allow simulation of cellular boundaries. ${ }^{22}$ This has been shown to significantly classify bladder mucosa ${ }^{9}$ and muscle disease, ${ }^{10}$ and has been suggested to be most useful for solid tissue such as skin, liver, or brain. ${ }^{20}$ For adenomatous tissue, the neighbourhood condition of O'Callaghan seems suitable, while the MST can be applied to any kind of tissue. The fourth method, adapted for soft tissue tumours, has been a decomposition of the MST to identify clusters cells. This has been used to significantly re-classify a range of sarcomas. Fibrosarcoma and malignant fibrous histiocytoma showed a lower number of clusters with a higher number of tumour cells per cluster, when compared with rhabdomyosarcoma and osteosarcoma. ${ }^{23}$ The variation in clusters may be of particular use in mixed cell uveal melanomas.

Syntactic structure analysis is a simple, fast but newly evolving technique. This is the first study to our knowledge on melanotic tumours. The prognostic significance of the percentage of cells with three neighbours, associated with the strong correlation of MST variables with cell type, has emerged using the MST approach. There were, however, only 28 tumour related deaths in the 92 patients studied. Further studies of even larger sample sizes should reveal additional information regarding the significance of MST variables. Greater numbers of measurements per tumour, either by lower magnification or larger field sizes, may further enhance reproducibility. Alternative applications, such as cluster analysis at various magnifications, decomposition of the MST, or use of O'Callaghan's and Voronoi's neighbourhood conditions, remain to be investigated. In conclusion, this preliminary study has established a strong correlation between tumour architecture, as described numerically by syntactic structure analysis, and the Callender cell types. Further investigations of this new and easy technique are necessary to optimise the role of syntactic structure analysis in the prediction of prognosis in patients with ocular melanoma.
Financial assistance from the Royal College of Surgeons in Ireland and the Royal Victoria Eye and Ear Hospital, Dublin, is gratefully acknowledged. The generous technical assistance of Jan Willem Theeuwes, Damien Tiernan, and Colma Barnes is appreciated.

1 Callender GR. Malignant melanotic tumours of the eye: a study of histologic types in 111 cases. Trans Am Acad Ophthalmol Otolaryngol 1931; 36: 131-42.

2 Iwamoto T, Jones IS, Howard GM. Ultrastructural comparisons of spindle-A, spindle-B, and epithelioid cells in uveal malignant melanoma. Invest Ophthalmol 1972; 11: 873.

3 Zimmerman LE. Malignant melanoma of the uveal tract. In: Spencer WH, ed. Ophthalmic pathology. Philadelphia: Saunders, 1986; Vol 3: 2093.

4 McLean IW, Foster WD, Zimmerman LE, Gamel JW. Modifications of Callender's classification of uveal melanoma at the Armed Forces Institute of Pathology. Am $\mathcal{F}$ Ophthalmol 1983; 96: 502-9.

5 Gamel JW, McCurdy JB, McLean IW. A comparison of prognostic covariates for uveal melanoma. Invest Ophthalmol Vis Sci 1992; 33: 1919-22.

6 Coleman K, Baak JPA, Dorman A, Mullaney J, Curran B, Tiernan D, et al. Deoxyribonucleic acid ploidy studies in choroidal melanomas. Am f Ophthalmol 1993; 115: 376-83.

7 Meecham WJ, Char DH. DNA content abnormalities and prognosis in uveal melanoma. Arch Ophthalmol 1986; 104: 1626-9.

8 Marcus DM, Minkovitz JB, Wardwell SD, Albert DM. The value of nucleolar organizer regions in uveal melanoma. Am F Ophthalmol 1990; 110: 527-34.

9 Prewitt JMS, Wu SC. An application of pattern recognition to epithelial tissues. In: Proceedings of Second Annual Symposium on Computer Applications in Medical Care, New York. 1978: 15-25.

10 Sanfeliu A, Fu KS, Prewitt JMS. An application of a distance measure between graphs to the analysis of muscle tissue patterns: report of the Workshop on Structural and Syntactic Pattern Recognition. Saratoga Springs, New York, 1981: 86-9.

11 Kayser K, Schlegel W. Pattern recognition in histo-pathology: basic considerations. Math Inform Med 1982; 21: 15.

12 Dussert C, Kopp F, Gandilhon P, Pourreau-Schneider N, Rasigni M, Palmari J, et al. Toward a new approach in tumour cell heterogeneity studies using the concept of order. Analytical Cellular Pathology 1989; 1: 123.

13 Kayser K, Stute H, Bubenzer J, Paul J. Combined morphometrical and syntactic structure analysis as tools for histomorphological insight into human lung carcinoma growth. Analyt Cell Pathol 1990; 2: 167-78.

14 Bibbo M, Kim DH, di Loreta C, Dytch HE, Galera-Davidson $\mathrm{H}$, Thompson $\mathrm{D}$, et al. Tissue architectural features for the grading of prostatic carcinoma. Analyt Quant Cytol Histol 1990; 12: 229-36.

15 Kayser K, Bosslet K, Ebert W, Kiefer B. Differential diagnosis of mesothelioma and metastatic adenocarcinomas of pleura by means of indirect immunoperoxidase technique combined with syntactic structure analysis. Tum Diagn Ther 1987: 28-35.

16 Kayser K, Shaver M, Modlinger F, Postl K, Moyers JJ. Neighborhood analysis of low magnification structures (glands) in healthy, adenomatous and carcinomatous colon mucosa. Path Res Pract 1986; 181: 153 .

17 Tezuka F, Sato I, Higashiiwai H, Endo N, Ito K, Kasai M. Method for the quantitative evaluation of the distribution pattern of nuclei in normal and malignant endometria epithelium. Analyt Quant Cytol Histol 1990; 12: 237-41.

18 van Diest PJ, Fleege JC, Baak JPA. Syntactic structure analysis in invasive breast cancer: analysis of reproducibility, biologic background, and prognostic value. Hum Pathol 1992; 23: 876-83.

19 Coleman K, Baak JPA, van Diest P, Mullaney J, Farrell M, Fenton M. Prognostic factors following enucleation of 111 uveal melanomas. Brf Ophthalmol 1993; 77: 688-92.

20 Kayser $K$. Neighborhood conditions and applications of syntactic structure analysis in histo-pathology. Acta Stereol 1987; $2: 373$.

21 Gamel JW, McLean IW. Quantitative analysis of the Callender classification of uveal melanoma cells. Arch Ophthalmol 1977; 95: 686-91

22 Voronoi $G$. Nouvelles applications des parametres continus a la theorie des formes quadratiques, deuxieme memoire: recherches sur les paralleloedres primitifs. $\mathcal{J}$ Reine Angew Math 1902; 134: 188.

23 Kayser K, Sandau K, Bohm G, Kunze KD, Paul J. Analysis of soft tissue tumours by an attributed minimum spanning tree. Analyt Quant Cytol Histol 1991; 13: 329. 